\title{
Anterior Inferior Hip Dislocation: Report of Three Cases and Review of Literature
}

\author{
Pratik Agarwal ${ }^{1}$, Siddharth Khadilkar ${ }^{2}$, Sunil Handralmath ${ }^{2}$, Madhav Khadilkar ${ }^{1}$ \\ Learning Point of the Article: \\ Luxatio erecta femoris can be managed with closed reduction under general anaesthesia, within $6 \mathrm{hrs}$ to decrease complications.
}

\section{Abstract}

Introduction: Inferior dislocation of the hip, also called luxatio erecta femoris, is the rarest type of hip dislocation with a poorly understood mechanism of injury. We came across three such cases resulting from high-energy trauma with various other associated injuries.

Case Report: The first patient, a 25-year-old man, presented with the right hip pain, hip and knee joint in flexion without rotational component, after motor vehicle collision. The second patient, a 42 -year-old man, presented with the left hip pain, hip and knee joint in flexion with rotational component, following fall from $20 \mathrm{ft}$ height. The third patient, a 29 -year-old lady, presented with the left hip pain, hip and knee joint in flexion with rotational component, after motor vehicle collision. All three patients were diagnosed by radiograph and were managed by closed reduction under short general anesthesia, within $3 \mathrm{~h}, 9 \mathrm{~h}$, and $6 \mathrm{~h}$, respectively. Thomas splint was used to immobilize the limb in all for 1 month and weightbearing was started after 2 months from injury. Two of them were followed up to 6 months and one was lost to follow up. No evidence of avascular necrosis of femoral head or other complication related to hip dislocation was noted.

Conclusion: Luxatio erecta femoris is a rare type of hip dislocation and with limited publication. The position of limb on presentation should raise the suspicion of same and diagnosis confirmed through radiological investigations. Usually, this type of dislocation can be managed with closed reduction. If closed reduction is unsuccessful, then a fracture femur or bone chip in the joint could be the cause of the difficulty.

Keywords: Hip, dislocation, inferior, luxatio erecta femoris.

\section{Introduction}

Inferior dislocation of the hip, also called luxatio erecta femoris or infracotyloid dislocation, is the rarest type of hip dislocation with a poorly understood mechanism of injury, mainly occurring from high-energy incidents, such as road traffic accidents or sports $[1,2,3,4]$. They represent $2-5 \%$ of all hip dislocations and can be obturator or ischial type, with the latter being more common $[4,5]$.

The hip joint is inherently stable due to the configuration of bony structure and the ligaments around it, thereby needing a strong force to cause dislocation here $[6,7]$.

Injuries are caused by two mechanisms [8, 9]. The obturator type involves a force applied to an abducted hip, which is then forced into flexion and externally rotation, leading to dislocation of the femoral head anterior and inferior to the obturator foramen.

The ischial type involves a force applied to the flexed hip and flexed knee, with the femur in extreme flexion with no abduction or external rotation of the thigh and it dislocates the femoral head inferiorly, lying next to the ischium [10].

In this article, we are reporting three cases of traumatic inferior hip dislocations, one ischial inferior hip dislocation and two cases of obturator inferior hip dislocation. All cases were managed with closed reduction. The literature review is aimed at increasing the understanding, guiding the surgeons for diagnosis and treatment of this uncommon injury.

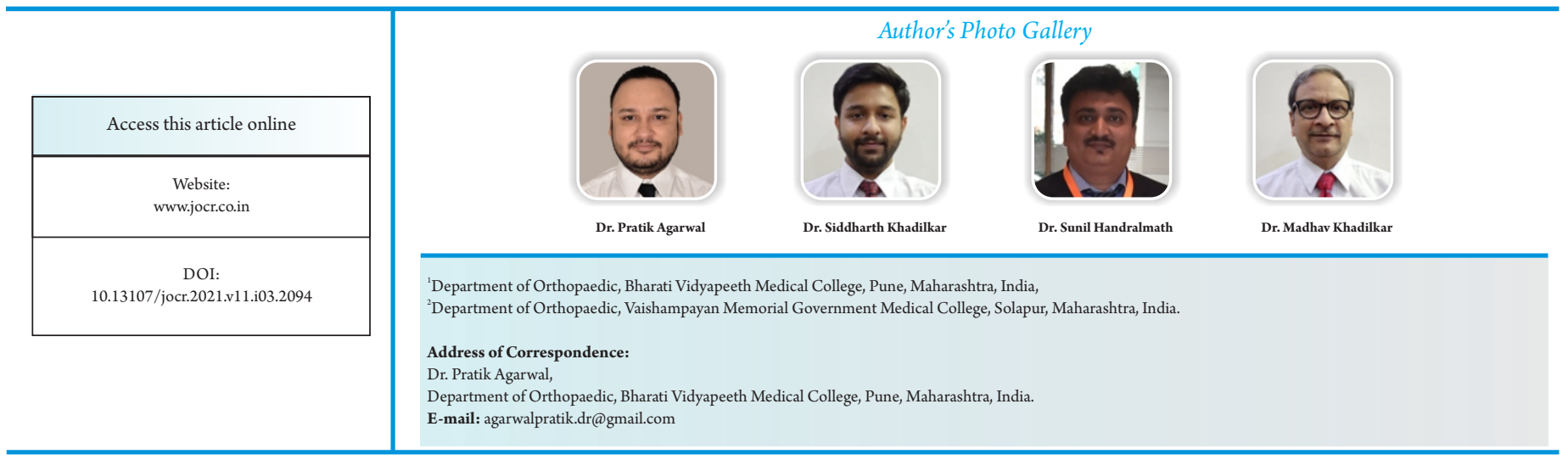

Journal of Orthopaedic Case Reports | pISSN 2250-0685 | eISSN 2321-3817 | Available on www.jocr.co.in | doi:10.13107/jocr.2021.v11.i03.2094 This is an Open Access article distributed under the terms of the Creative Commons Attribution Non-Commercial License (http://creativecommons.org/licenses/by-nc/3.0) which permits unrestricted non-commercial use, distribution, and reproduction in any medium, provided the original work is properly cited. 


\begin{tabular}{|c|c|c|c|c|c|c|c|c|}
\hline Age & Sex & Mode of injury & Attitude of limb & Associated injuries and diagnosis & Method of reduction & $\begin{array}{c}\text { Post-reduction } \\
\text { neurovascular status }\end{array}$ & Post-reduction protocol & $\begin{array}{c}\text { Complication at } \delta \\
\text { months }\end{array}$ \\
\hline 25 & M & $\begin{array}{l}\text { Road traffic } \\
\text { accident }\end{array}$ & $\begin{array}{l}\text { At hip joint- } \\
\text {-flexion } 90^{*} \\
\text { abduction } 10^{*} \\
\& \text { rotation absent. } \\
\text { - At knee joint- } \\
\text {-flexion } 140^{*} \\
\quad \text { (Fig 1g-1) }\end{array}$ & $\begin{array}{l}\text { Undisplaced fracture of posterio: } \mathrm{p} \\
\text { lip of right acetabulum with a } \\
\text { contused lacerated wound over } \\
\text { right leg. Ischial type (Fig.la-f) }\end{array}$ & $\begin{array}{l}\text { Under short GA, patient in supine } \\
\text { position, closed reduction done within } 3 \\
\mathrm{~h} \text { of injury, by applying axial traction } \\
\text { along the long axis of femur by } 1 \\
\text { surgeon, while pelvis was stabilized by } \\
\text { the } 2^{\text {nd }} \text { surgeon (Fig.li) }\end{array}$ & Intact & $\begin{array}{l}\text { Immobilized in Thomas splin } \\
\text { for } 1 \text { month. } \\
\text { At } 1 \text { month -ROM exercise. } \\
\text { At } 2 \text { months - Partial weigltt- } \\
\text { bearing. } \\
\text { At } 4 \text { months - Full weight. } \\
\text { bearing }\end{array}$ & nt \\
\hline 42 & M & $\begin{array}{c}\text { Fall from } 20 \mathrm{ft} \\
\text { height }\end{array}$ & $\begin{array}{l}\text { At hip joint- -flexion } 50^{*} \text { - } \\
\text { abduction } 20^{*} \text {-external } \\
\text { rotation } 90^{*} \text { At knee joint- - } \\
\text { flexion } 40^{*}\end{array}$ & $\begin{array}{l}\text { Craniocerebral injury with } \\
\text { transverse process fracture of } L 1 \\
\text { and } \mathrm{L} 2 \text { vertebrae. Obturator type } \\
\text { (Fig.2a-b) }\end{array}$ & $\begin{array}{l}\text { Under short GA, patient in supine } \\
\text { position, closed reduction done within } 9 \\
\mathrm{~h} \text { of injury, by maintaining traction } \\
\text { followed by gradual extension of knee } \\
\text { joint with some internal rotation. }\end{array}$ & Intact & $\begin{array}{l}\text { Immobilized in Thomas splin } \\
\text { for } 1 \text { month. At } 1 \text { month } \\
\text {-ROM exercise. }\end{array}$ & $\begin{array}{l}\text { Lost to follow up } \\
\text { after } 1 \text { month }\end{array}$ \\
\hline 29 & $\mathrm{~F}$ & $\begin{array}{l}\text { Road traffic } \\
\text { accident }\end{array}$ & $\begin{array}{l}\text { At hip joint flexion - } 70^{*} \\
\text { abduction - } 30^{*} \text { external } \\
\text { rotation } 90^{*} \text {. At knee joint- } \\
\text { flexion } 80^{*}\end{array}$ & $\begin{array}{c}\text { Left side chest contusion, liver } \\
\text { laceration with splenic injury, } \\
\text { contused lacerated wound over } \\
\text { both hand and multiple abrasior } \\
\text { over the left lower limb. Obturator } \\
\text { type (Fig.3a-b) }\end{array}$ & $\begin{array}{l}\text { Under short GA, patient in supine } \\
\text { position, closed reduction done within } 6 \\
\mathrm{~h} \text { of injury, by maintaining traction } \\
\text { followed by gradual extension of knee } \\
\text { joint with some internal rotation. }\end{array}$ & Intact & $\begin{array}{l}\text { Immobilized in high above } \\
\text { knee cast for } 1 \text { month. At } 1 \\
\text { month -ROM exercise. At } 2 \\
\text { months - Partial weight- } \\
\text { bearing. At } 4 \text { months - Full } \\
\text { weight-bearing. }\end{array}$ & 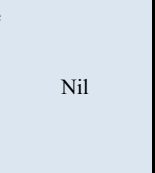 \\
\hline
\end{tabular}

\section{Case Report}

Three cases of inferior hip dislocation were encountered by us between January 2019 and December 2019. Case 1 was 25yrs old man with ischial type of inferior hip disclocation (Fig. 1a-i). Case 2 was 42 yrs old man with obturator type of inferior hip dislocation (Fig. 2a-b). Last case was 29 yrs old lady with obturator type of inferior hip dislocation (Fig. 3a-b). Details of the cases are as follows in Table 1:

\section{Discussion}

An inferior dislocation is a rare type of hip dislocation with only about 14 articles reporting it, as shown by a study by Jain et al. [10]. It reported 13 men and 4 women, aged 5-56 (mean, 23) years with 16 unilateral and one bilateral inferior dislocation of the hip [10].

Literature review revealed that most patients presented with an ischial-type dislocation, with extreme hip flexion, prominence of the greater trochanter, and the thigh touching the anterior abdominal wall, whereas some presented with varying degrees of flexion, abduction, and external rotation, indicating an associated fracture, a chronic injury, or an obturator-type dislocation $[8,9,10,11,12]$.

In the present study, the patient with ischial type dislocation had marked flexion, whereas in obturator types, there was relatively less flexion with abduction and extreme external rotation.

Inferior hip dislocation can be managed with closed reduction

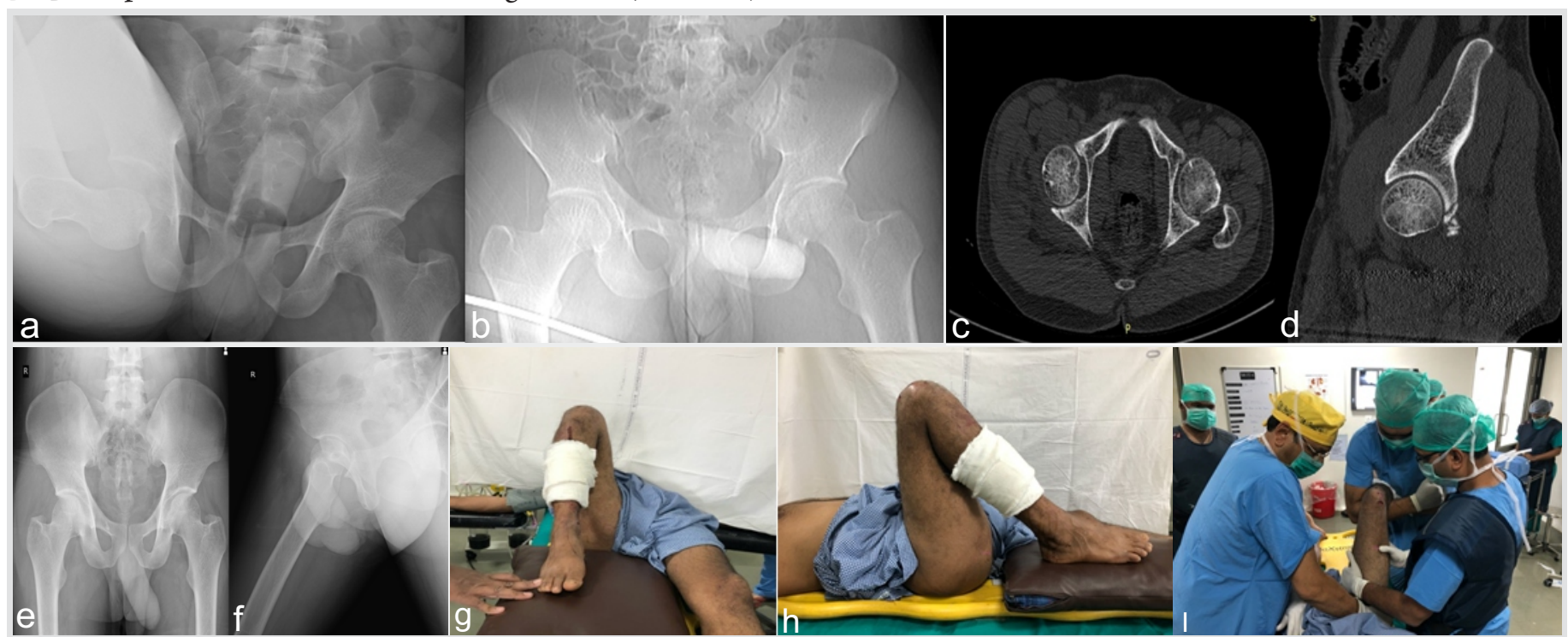

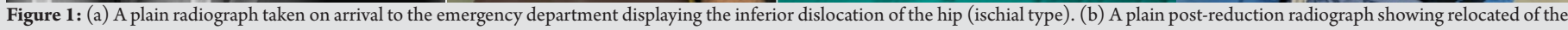

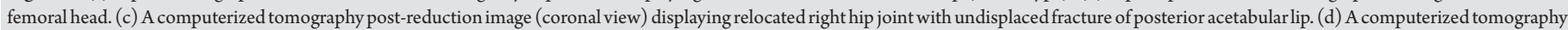

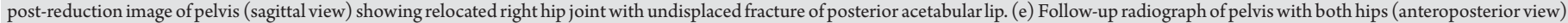

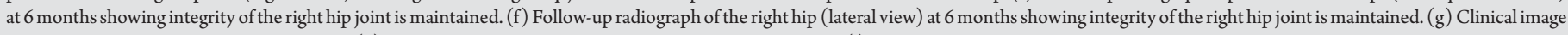
showing attitude of lower limb pre-reduction. (h) Clinical image showing attitude of lower limb pre-reduction. (i) Reduction maneuver. 


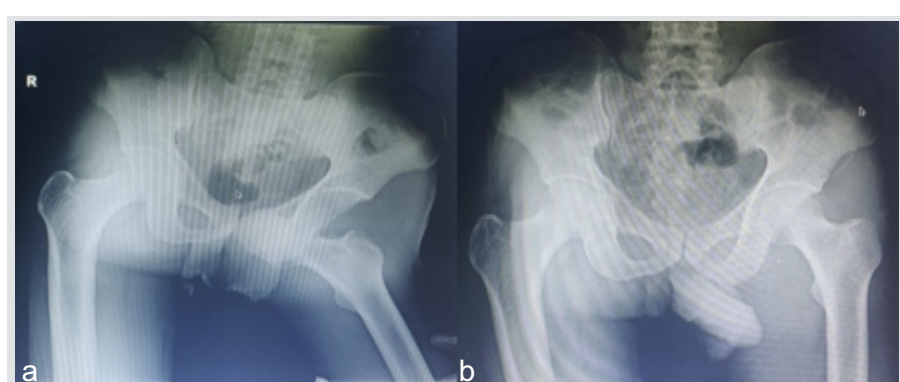

Figure 2: (a) A plain radiograph taken on arrival to the emergency department displaying the inferior dislocation of the hip (obturator type). (b) A plain post-reduction radiograph showing relocated of the femoral head.

under general anesthesia or sufficient sedation. Reduction is usually achieved by maintaining traction and gradual knee extension with some internal rotation if needed $[1,9,13]$.

In the present study, all three patients were treated nonoperatively and had good outcome clinically and radiologically. Out of three cases, two hip dislocations were relocated within 6 $\mathrm{h}$, whereas one relocation was done within $9 \mathrm{~h}$ from injury. Alli's maneuver was done for hip relocation, in which the patient was supine, with an assistant stabilizing the pelvis, the knee was flexed and lateral traction was applied to the inner side of the thigh, along with this longitudinal traction (in line with the axis of the femur). Then, hip joint was gently adducted and internally rotated to achieve the reduction.

An important complication following traumatic dislocation of the hip is prolonged and irreversible ischemia of the head of the femur leading to osteonecrosis in $10-30 \%$ or more of cases, particularly if the dislocation is accompanied by severe bone destruction [14]. Hip dislocations should ideally be reduced within $6 \mathrm{~h}$ to prevent and minimize complications [14].

Radiological and clinical assessment was done at 6 months. Two patients followed up, had no sign of instability, and had full range of movement. Both patients were walking full weightbearing. However, one patient was lost to follow up at 6 months.

\section{Limitation}

Follow-up of all three patients is not adequate to comment on complications related to inferior hip dislocation such as

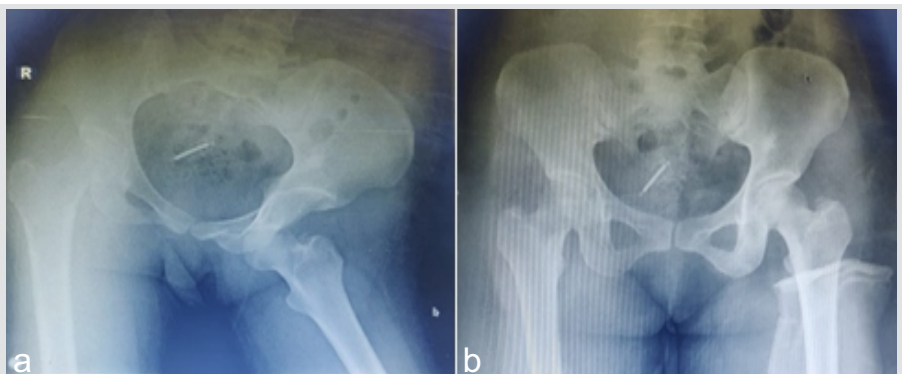

Figure 3: (a) A plain radiograph taken on arrival to the emergency department displaying the inferior dislocation of the hip (obturator type). (b) A plain post-reduction radiograph showing relocated of the femoral head.

avascular necrosis (AVN) of femoral head and osteoarthritis which need longer follow-up for at least $3-5$ years.

\section{Conclusion}

Luxatio erecta femoris is a rare type of hip dislocation and with limited publication. The position of limb on presentation should raise the suspicion of same and diagnosis confirmed through radiological investigations such as X-ray and CT. Concomitant extremity fractures with additional vital organ injuries may lead to life-threatening condition. Usually, this type of dislocation can be managed with closed reduction under sufficient general anesthesia and muscle relaxant. Reduction should be done within $6 \mathrm{~h}$ to decrease complications. If closed reduction is unsuccessful, then a fracture femur or bone chip in the joint could be the cause of the difficulty. Follow-up is important to monitor any signs of AVN and osteoarthritis.

\section{Clinical Message}

Clinical suspicion and radiological investigations (X-ray and CT scans) are important for early diagnosis inferior hip dislocation. Associated fracture femur or bone chip in the joint may be suspected in case of a failed closed reduction, which will require open reduction to relocate the hip joint. More case reports, studies, and a long-term follow-up are required for more information on incidence of any signs of AVN and osteoarthritis.

\section{References}

1. Abad Rico JI, Barquet A. Luxatio erecta of the hip. A case report and review of the literature. Arch Orthop Trauma Surg 1982;99:277-9.

2. Hung NN. Traumatic hip dislocation in children. J Pediatr Orthop B 2012;21:542-51.

3. Avery DM, Carolan GF. Traumatic obturator hip dislocation in a 9-year-old boy. Am J Orthop (Belle Mead NJ) 2013;42:E81-3.

4. Dudkiewicz I, Salai M, Horowitz S, Chechik A. Bilateral asymmetric traumatic dislocation of the hip joints. J Trauma 2000;49:336-8.

5. Phillips AM, Konchwalla A. The pathologic features and mechanism of traumatic dislocation of the hip. Clin Orthop Relat Res 2000;377:7-10.

6. Tekin AÇ, Çabuk H, Büyükkurt CD, Dedeoğlu SS, İmren Y, Gürbüz H. Inferior hip dislocation after falling from height: A case report. Int J Surg Case Rep 2016;22:62-5.

7. Dreinhöfer KE, Schwarzkopf SR, Haas NP, Tscherne H. 
Isolated traumatic dislocation of the hip. Long-term results in 50 patients.J Bone Joint Surg Br 1994;76:6-12.

8. Ferguson KL, Harris VV. Inferior hip dislocation in an adult: Does a rare injury now have a common mechanism? Am J Emerg Med 2000;1:117-8.

9. Ismael S, Vora J, Thomas P. Adult traumatic inferior hip dislocation: Rare case ended with open reduction. J Orthop Case Rep 2017;7:101-4.

10. Jain S, Haughton BA, Grogan RJ. Inferior dislocation of the (Hong Kong) 2015;23:123-6. hip: A case report and literature review. J Orthop Surg

11. Singh R, Sharma SC, Goel T. Traumatic inferior hip dislocation in an adult with ipsilateral trochanteric fracture. JOrthop Trauma 2006;20:220-2.

12. Pankaj A, Sharma M, Kochar V, Naik VA. Neglected, locked, obturator type of inferior hip dislocation treated by total hip arthroplasty. Arch Orthop Trauma Surg 2011;131:443-6.

13. Beauchesne R, Kruse R, Stanton RP. Inferior dislocation (luxatio erecta) of the hip. Orthopedics 1994;17:72-4.

14. Tawari AA, Bahuva VD, Goregaonkar AB, Subaraman R. A rare case of open anterior hip dislocation. J Surg Case Rep 2013;2013:rjs035.

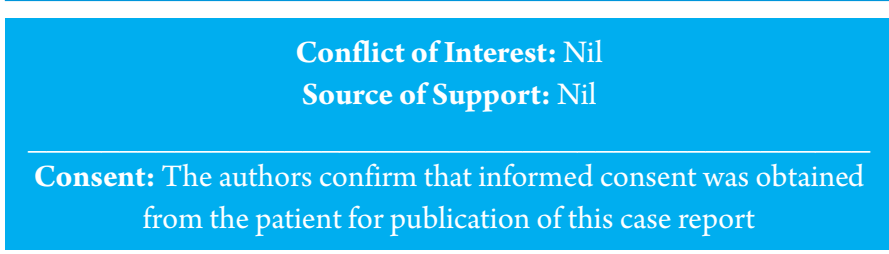

How to Cite this Article

Agarwal P, Khadilkar S, Handralmath S, Khadilkar M. Anterior Inferior Hip Dislocation: Report of Three Cases and Review of Literature. Journal of Orthopaedic Case Reports 2021 March;11(3): 71-74. 